\title{
Arin \\ Implementasi Penginputan Dan Pelaporan Keuangan Manajemen Masjid Wilayah Sumatera Selatan
}

\section{Chandra Satria}

Program Studi Ekonomi Syariah STEBIS IGM Palembang

Email : chandras@stebisigm.ac.id

\begin{abstract}
This Community Service (PKM) collaborates with community organizations, namely the Imam Mosque Brotherhood Association (IPIM) for the South Sumatra Region. This activity is carried out with the aim of providing motivation and guidance for mosque administrators, especially the mosque's financial responsibility department to be able to manage and account for mosque finances, not only must be based on sharia law but also must have financial managerial capabilities in the form of professional accountability that is accountable and transparent. The mosque's financial management management applies actual cash basic accounting principles for non-profit organizations. In this PKM, the participants in this mosque's financial management training are mosque administrators around the city of Palembang and outside the city of Palembang which are carried out online and offline. This training aims to provide and offer the following solutions: (1) Develop a mosque foundation financial reporting system in the form of systems and procedures for managing funds. (2) Provide training, and coaching to mosque administrators, especially the financial section of the transaction process which will later produce financial reports. The output target of this PKM is to improve the financial management of mosques that are more professional in producing accountable and transparent mosque financial reports, both in the form of presentation and management of mosque funds. The realization of the implementation of this training program produces the following outputs: Knowledge of the implementation of the mosque management in the finance department to be able to compile and report mosque financial accountability using the DKM application.
\end{abstract}

Keywords: Mosque Bookkeeping, Mosque financial reports, Mosque financial applications, DKM applications

\begin{abstract}
Abstrak
Pengabdian Kepada Masyarakat (PKM) ini bekerjasama dengan Organisasi masyarakat yaitu Ikatan Persaudaraan Imam Masjid (IPIM) Wilayah Sumatera Selatan. Kegiatan ini dilaksanakan dengan tujuan untuk memberikan motivasi dan pedoman bagi pengurus masjid terutama bagian pertanggungjawaban keuangan masjid agar mampu mengelolah dan mempertanggungjawabkan keuangan masjid tidak hanya harus berprinsip pada hukum shariah tetapi juga harus memiliki kemampun manajerial keuangan dalam bentuk pertanggungjawaban professional yang akuntanbel dan transparan. Tatakelola manajemen keuangan masjid menerapkan akuntansi berprinsip cash basic yang actual bagi organisasi non profit.. Dalam PKM ini yang menjadi peserta dalam pelatihan manajemen keuangan masjid ini ada pengurus masjid sekitar kota palembang dan luar kota palembang yang dilaksanakan secara daring dan luring. Pelatihan ini bertujuan
\end{abstract}


memberikan dan menawarakan solusi berikut: (1) Menyusun sistem pelaporan keuangan yayasan Masjid dalam bentuk sistem dan prosedur pengelolaan dana. (2) Memberikan pelatihan, dan pembinaan kepada pengurus masjid khususnya bagian keuangan proses jalannya transaksi yang nantinya akan menghasilkan laporan keuangan. Target luaran PKM ini adalah peningkatan pengelolaan manajemen keuangan masjid yang lebih professional dalam menghasilkan laporan keuangan masjid yang akuntabel, transparan baik dalam bentuk penyajian maupun pengelolaan dana masjid. Realisasi pelaksanaan program pelatihan ini menghasilkan luaran sebagai berikut: Pengetahuan implementasi pengurus masjid bagian keuangan untuk dapat menyusun dan melaporakan pertanggungjawaban keuangan masjid dengan penggunaan aplikasi DKM.

Kata Kunci: Pembukuan Masjid, Laporan keuangan masjid, Aplikasi keuangan masjid, Aplikasi DKM

\section{Pendahuluan}

Data Kementerian Agama Republik Indonesia tercatat pada tahun 2020 jumlah masjid di Indonesia sebanyak 278.699 Masjid. Sedangkan di sumatera selatan sendiri berjumlah 6979 dan kota palembang berjumlah 779 masjid di tahun 2013. Keberadaan masjid merupakan wujud manifestasi umat Islam untuk dapat melaksanakan ibadah dengan nilai ibadah yang lebih baik dan membangun tingkat kebersamaan dalam rangka mewujudkan persatuan yang dinaungi oleh kegiatan pelaksanaan ibadah bersama-sama di Masjid. Memakmurkan masjid menjadi tanda kemajuan peradaban Islam. Hal ini bisa kita lihat sejarah di awal Islam muncul bagaimana Nabi Muhammad SAW menjadikan Masjid sebagai pusat ibadah, aktivitas sosial, ekonomi, dan juga politik (Utaberta et al., 2015). Masjid memiliki fungsi yang sangat luas tidak hanya memfasilitasi umat untuk melaksanakan ibadah tetapi juga dapat melakukan berbagai aktivitas lainnya dalam bentuk kegiatan muamalah sesame manusia sebagaimana ditunjukkan oleh Mohd Taib et al. (2016). Nabi Muhammad SAW memakmurkan masjid tidak hanya menampilkan estetika bangunannya, namun lebih kepada fungsi dalam membangun nilai-nilai kehidupan masyarakat sekitar.

Nilai kehidupan yang tidak hanya menguatkan dalam tingkat peribadatan ke sang khalik tetapi juga membangun suatu kekuatan sesama manusia untuk mencapai kesejahteraan di dunia. Jika melihat salah satu fungsi masjid dalam sudut padang sosial, maka masjid juga memiliki fungsi memberikan dampak peningkatan status sosial ekonomi masyarakat setempat penyaluran dana-dana infak, sodaqoh, zakat dan lain sebagainya yang diterima oleh masjid oleh pemberian masyarakat. Rosul SAW juga menempatkan masjid sebagai tempat pengaturan dan pengelolaan keuangan umat guna memberikan dapat kesejahteraan sosial baik dalam bentuk penguatan keuangan mendukung pengelolaan jalannya pemerintahan dan juga penguatan ekonomi umat secara umum. Masjid menerima dana baik dari masyarakat langsung dalam bentuk celengan atau sumbangan yang dibungkus dalam bentuk pembayaran zakat, infak serta sodaqoh. Fungsi ini mengharuskan manajemen masjid untuk dapat mengelola mulai dari bentuk pencatatan penerimaan, pengeluaran serta bentuk laporan keuangan keseluruhan yang harus dipertanggungjawbkan kepada masyarakat sekitar dan Tuhan Yang Maha Esa.

Melihat kondisi pengelolaan manajemen masjid dibeberapa wilayah termasuk palembang dan sekitar nya, penulis melihat masih banyak dari pengurus masjid khsusunya bidang keuangan dan pembukuan melakukan proses pencatatan baik penerimaan dan pengeluaran dengan sangat sederhana melalui penggunaan 
pencatatan manual dibuku yang diformat sesuai dengan kebutuhan masing-masing pengurus. Hal ini memberikan gambaran bagaimana sumber daya manusia dalam penguruan masjid melakukan pengelolaan keuangan masjid berdasarkan pengalaman atau yang biasa dilakukan oleh pengurus sebelumnya. Melihat hal ini membuat penulis tertarik untuk memberikan pelatihan dan panduan pemanfaatan aplikasi sederhana keuangan masjid yang dapat dijadikan salah satu alternative pengurus masjid untuk dapat melakukan pencatatan dan pembukuan secara lebih baik, transparan dan tersistematis melalui pemanfaatan teknologi informasi pencatatan keuangan masjid.

\section{Metode Pengabdian}

1. Tahap Persiapan

a. Survei tempat pelaksanaan kegiatan.

b. Melaksanakan observasi dan wawancara ke beberapa pengurus masjid seperti Masjid Agung, Masjid Darussalam, dan lainnya untuk menentukan prioritas permasalahan yang harus segera diselesaikan.

c. Melakukan proses pengumpulan data guna mempersiapkan bahan dalam proses perancangan modul.

d. Pembuatan proposal.

e. Persiapan sarana dan sosialisasi untuk kegiatan pelatihan dan penawaran paket pelatihan

2. Tahap Pelaksanaan Kegiatan

Pelaksanaan kegiatan pengabdian melalui pembinaan dan pelatihan ini terdiri dari beberapa kegiatan diantaranya:

a. Analisis kebutuhan: Merupakan rangkaian kegiatan yang ditujukan untuk menemukan kebutuhan yang diperlukan untuk meningkatkan pengelolaan manajemen keuangan masjid dengan lebih baik akuntabel serta transparan.

b. Perancangan: merupakan suatu proses dalam merancang kegiatan pembinaan dan pelatihan dalam pemanfaatan Aplikasi keuangan masjid DKM.

c. Implementasi sosialisasi Pembinaan dan pelatihan pemanfaatan aplikasi keuangan DKM.

d. Pembinaan dan Pelatihan : melaksanakan sesuai dengan tujuan yang akan dicapai, yaitu memberikan materi pembinaan dan pelatihan penggunaan aplikasi keuangan masjid DKM untuk seluruh peserta.

3. Tahap Akhir

Setelah pelaksanaan kegiatan pembinaan dan pelatihan ini, maka dilanjutkan dengan beberapa kegiatan berikut:

a. Melaksanakan penginstalan aplikasi keuangan masjid DKM untuk seluruh peserta sebagai perwakilan pengurus masjid di wilayah palembang dan sumatera selatan.

b. Melakukan evaluasi kegiatan pelatihan menggunakan kuesioner sejauh mana pemanfaatan implementasi tindak lanjut pelatihan dan dampaknya terhadap pemanfaatan aplikasi keuangan masjid DKM oleh pengurus masjid.

c. Evaluasi keberhasilan kegiatan ini adalah melalui quesioner kepada peserta dalam penginstalan dan pemanfaatan aplikasi keuangan masjid DKM.

d. Melihat berapa banyak peserta dalam mengimplementasikan aplikasi manajemen keuangan masjid DKM guna diterapkan dalam pengelolaaan pencatatan dan pelaporan keuangan masjid masing masing peserta.

e. Pembuatan laporan hasil kegiatan.

d. Pengumpulan laporan hasil kegiatan 


\section{Pelaksanaan Kegiatan Pelatihan}

Kegiatan pelatihan dan sosialisasi ini dilaksanakan pada tanggal 30 Maret 2021 dimulai pagi session pertama pukul 09.00 dan selesai 12.00. Kegiatan dilaksanakan dengan sosialisasi dengan para pengurus peserta pelatihan. Lokasi pusat pelatihan di laksanakan di ruang aula lantai 3 (tiga) IGM dan media visua melalui zoom link.

Rundown kegiatan pelatihan dapat dilihat pada tabel 1 di bawah ini:

\begin{tabular}{|c|c|c|c|c|}
\hline No. & Tanggal & Pukul & Kegiatan & Keterangan \\
\hline 1. & 30 Maret 2021 & 09.00 & Persiapan & $\begin{array}{l}\text { Diikuti } 55 \\
\text { peserta terdiri } \\
\text { dari peserta } \\
\text { pengurus } \\
\text { masjid IPIM }\end{array}$ \\
\hline 2 & & $\begin{array}{l}09.15- \\
10.45\end{array}$ & $\begin{array}{l}\text { Pemafaran materi } \\
\text { dan sosialisasi }\end{array}$ & Narasumber \\
\hline 3 & & $\begin{array}{l}10.45- \\
11.30\end{array}$ & $\begin{array}{l}\text { Implementasi } \\
\text { penginstalan aplikasi } \\
\text { keuangan masjid } \\
\text { DKM }\end{array}$ & Narasumber \\
\hline 4 & & $\begin{array}{l}11.30- \\
12.00\end{array}$ & $\begin{array}{l}\text { Diskusi dan Tanya } \\
\text { jawab }\end{array}$ & Panitia \\
\hline 5 & & $\begin{array}{l}12.00- \\
12.15\end{array}$ & $\begin{array}{l}\text { Pengisian feed back } \\
\text { questioner } \\
\text { kegiatan. }\end{array}$ & \\
\hline 6 & & 12.30 & Selesai & \\
\hline
\end{tabular}

\section{Hasil dan Pembahasan}

Kegiatan pengabdian masyarakat yang berjudul" IMPLEMENTASI PENGINPUTAN DAN PELAPORAN KEUANGAN MANAJEMEN MASJID WILAYAH SUMATERA SELATAN" untuk manajemen keuangan masjid wilayah palembang dan sumatera selatan telah dilaksanakan pada hari selasa tanggal 30 maret 2021 melalui sarana pelatihan secara daring dan luring dan dilanjutkan dengan berikut beberapa Slide materi Pelatihan.

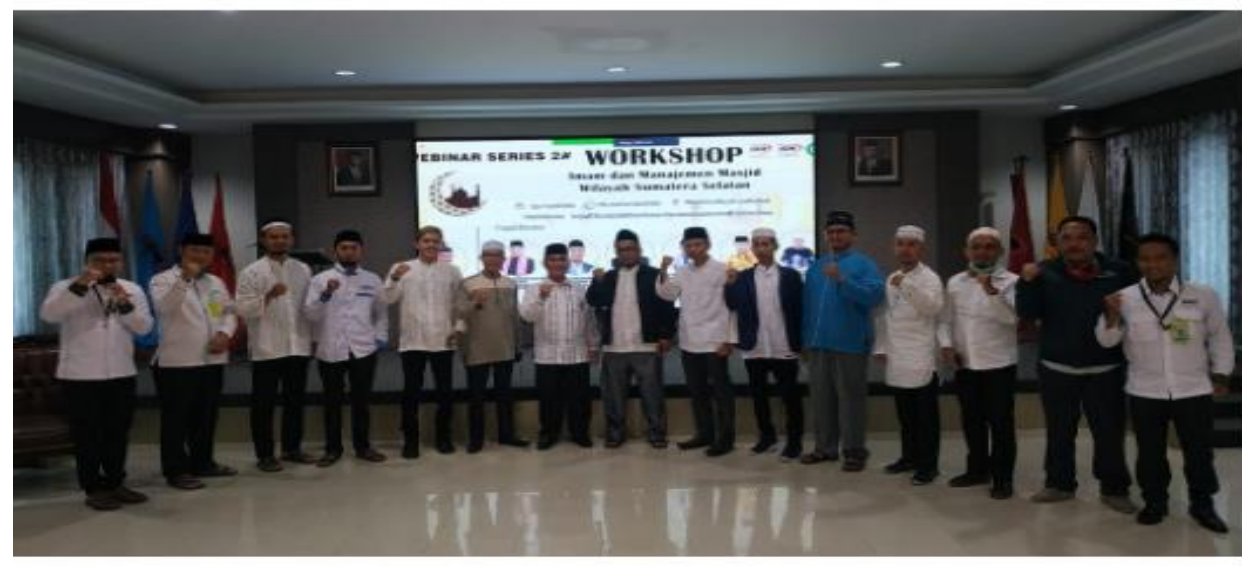


1. Materi ke-1 dari Ketua Umum IPIM dan Imam Besar Mesjid Istiqlal, Prof Dr KH Nasarudin Umar, MA, PhD; “ Dasar -dasar dan Syarat Menjadi Imam Masjid. Ketua Umum IPIM dan Imam Besar Mesjid Istiqlal, Prof Dr KH Nasarudin Umar, MA, PhD berharap agar para imam yang ada di Indonesia, tidak hanya mengerti soal tata cara dan syarat untuk memimpin salat.

Menurutnya seorang imam harus benar benar paham jika dirinya merupakan pemimpin spiritual baik saat di dalam masjid maupun di lingkungan sekitar. "Imam harus memiliki pengetahuan yang cukup, misalkan sosiologi, kesehatan masyarakat, antropologi, hukum bahkan mengetahui informasi publik yang saat ini tengah berkembang. Ini tantangan imam di era milenial,

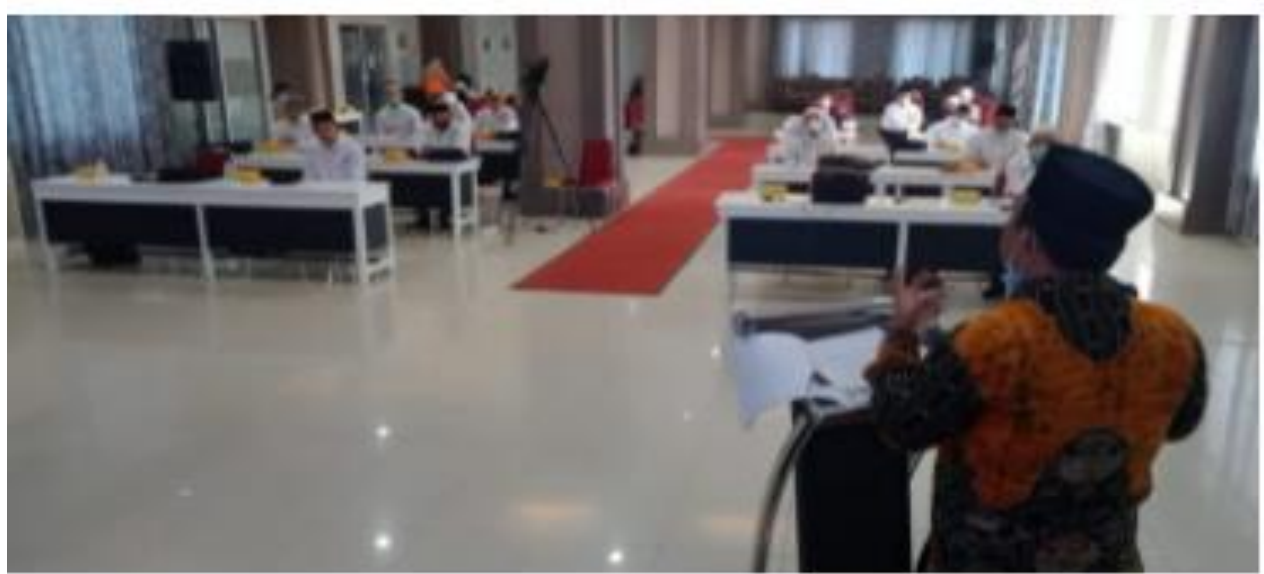

2. Materi ke-2 Pelatihan Manajemen Masjid dari Dewan Masjid Indonesia (DMI) Sumatera Selatan

Manajemen masjid modern yang berlandaskan pada nilai-nilai masjid pada zaman Rasulullah SAW yang dimana masjid menjadi jantung pokok kegiatan masyarakat serta bermanfaat bagi kesejahteraan masyarakat sekitar. Manajemen pengelolaan masjid sangat terkait dengan upaya memperbaiki Management kepengurusan; management kesekretariatan; management keuangan; Management dana dan usaha; management pembinaan jama'ah; management pendidikan dan pelatihan. Sedangkan, pengelolaan remaja masjid lebih ditekankan pada pembentukan kepengurusan remaja masjid dalam menjalankan peran dan fungsi remaja masjid yang meliputi memakmurkan masjid, kaderisasi umat dan generasi, pembinaan remaja muslim melalui kajian rutin, mendukung kegiatan takmir masjid termasuk dakwah dan sosial kemasyarakatan.

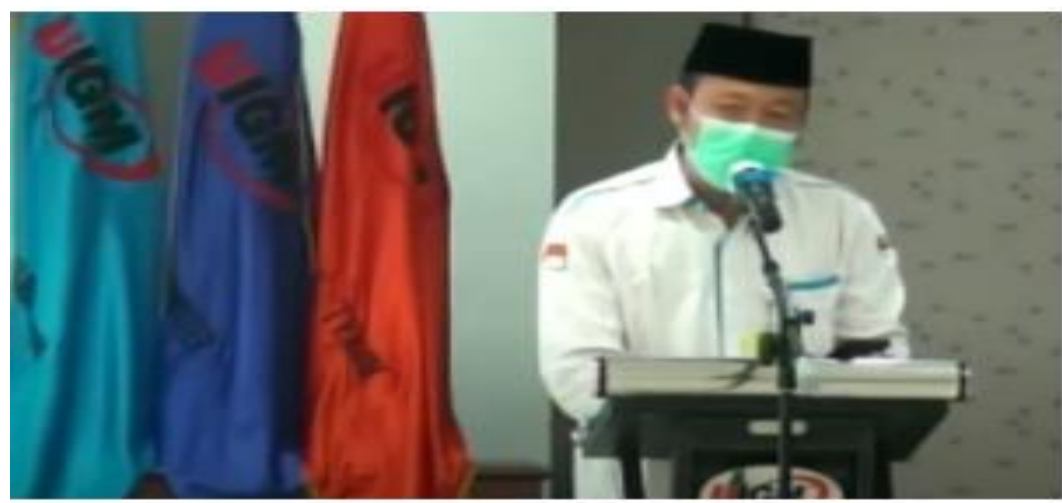


3. Materi ke-3 " Fiqh dan rukun wajib dan Sunnah Ketua Umum IPIM Wilayah Sumsel dan Imam Besar SMB JW Palembang, KH A Nawawi Dencik Al Hafidz

Kata "imam" memiliki dua makna. Dalam sholat, imam merujuk pada orang yang berdiri di depan serta memimpin jamaah sholat. Sedangkan makna lainnya, imam adalah gelar bagi seseorang yang memegang kepemimpinan atau kekuasaan. Tidak semua orang boleh menjadi imam dalam sholat. Ada beberapa syarat yang harus dipenuhi agar seseorang bisa menjadi imam dalam sholat berjamaah.

4. Materi ke-4 " Manajemen Pengelolaan Keuangan dan Aset Masjid oleh H. Chandra Satria, S.E, M.Si dan Doly Nofiansyah, S.E, M.Si

Lembaga Keuangan Masjid Adalah sesuatu yang memiliki unsur-unsur seperti struktur, manajemen, fungsi, hak dan kewajiban terkait pengelolaan keuangan masjid sebagai sentral kegiatan keagamaan umat Islam Sumber Pemasukan / Pendanaan Sumber pemasukan keuangan masjid umumnya bersumber dari Zakat, Infaq, Shodaqoh, dan Wakaf serta Usaha ekonomi yaitu dana yang diperoleh dengan melakukan aktivitas ekonomi khususnya di bidang perdagangan dan jasa. Yang berfungsi Menambahkan informasi tentang Masjid. Seperti nama, alamat, dan fasilitas Masjid. Jadwalkan kegiatan Masjid yang akan berlangsung dengan mudah Kegiatan surat-menyurat menjadi mudah. Buat blog yang bermanfaat tentang Masjid anda. Sharing pengalaman selama manajemen masjid dengan masjid lain. Kelola Keuangan Dengan Mudah DKM dapat mengelola data keuangan Masjid secara rinci. Penelusuran transaksi dengan mudah Cetak Laporan keuangan secara mudah dan cepat Laporan keuangan tersedia online dan dapat diakses oleh jamaah COA digenerate standar dan sesuai dengan SAK ETAP (Standar Akuntansi).

\section{Pengenalan program aplikasi DKM}

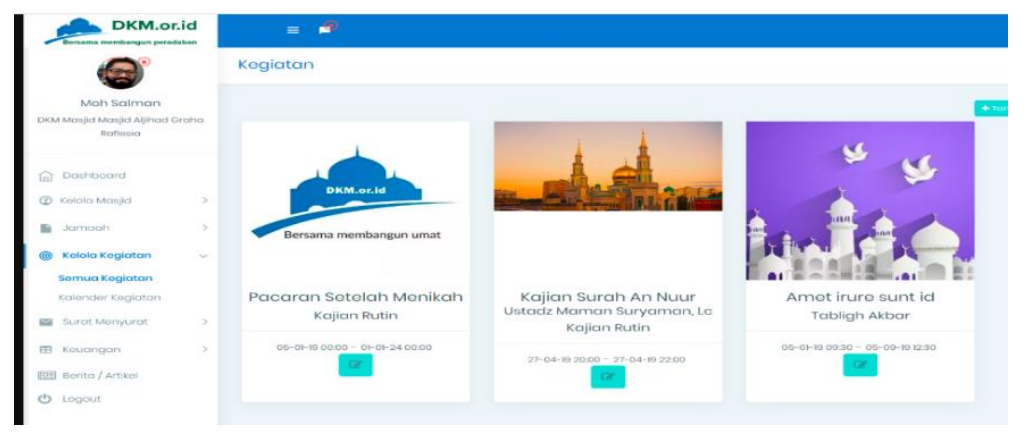

5. Identifikasi Masalah di manajemen keuangan masjid wilayah palembang dan sekitarnya

Kegiatan awal sebelum melaksanakan kegiatan pembinaan dan pelatihan ini diawali dengan komunikasi awal bersama beberapa pengurus masjid dan perwakilan ikatan persaudaraan imam masjid (IPIM) wilayah sumatera selatan. Hal ini bertujuan untuk mendapatkan informasi terkait dengan permasalahan pengelolaan dan pencatatan keuangan masjid. Wawancara dan diskusi yang telah dilakukan oleh tim pengabdian masyarakat terhadap pengurus manajemen masjid di beberapa wilayah kota palembang dan sekitarnya. Hasil diperoleh bahwa pengelolaan dan pencatatan dana masjid masih dilakukan secara manual dengan penggunaan buku tulis yang diformat untuk pencatatan sederhana melalui bagian keuangan yang diberikan tugas sebagai fungsi keuangan masjid. Terdapat 
beberapa masalah dan kendala yang muncul seperti waktu perekapan data dan tracer penggunaan dana belum dapat dilihat dalam bentuk penyajian laporan keuangan secara keseluruhan.

Pelatihan dan sosialisasi rencana usaha ini dilakukan sebagai bentuk solusi awal untuk memberikan altenarif aplikasi yang dapat membantu pengelolaan dan pencatatan keuangan masjid dengan lebih tersistematis, transparan serta informative kapada pengurus masjid dan pihak pihak terkait.

\section{Penentuan Metode Pelatihan dan sosialisasi pemanfaatan Situs WEB Usaha} STEBIS IGM

Terdapat banyak sekali metode pelatihan dan sosialisasi yang dapat diberikan kepada peserta kegiatan pengabdian masyarakat. Metode pelatihan yang disiapan menurut teori Cherrington (1995), menjadi dua yaitu on the job traning dan off the job training. Metode pelatihan dan sosialisasi yang sesuai dalam kegiatan ini adalah metode pendekatan lecture yaitu bagian dari off the job training yaitu pelatihan dimana menyampaikan berbagai macam informasi kepada sejumlah besar orang pada waktu bersamaan. Kegiatan pelatihan dan sosialisasi dilaksanakan secara luring dengan jumlah terbatas maksimal 20 peserta melalui protokol kesehatan dalam kondisi massa covid 19 yang sedang berlangsung di tahun 2021 ini serta daring bagi peserta yang berasal dari luar kota Palembang.

Jumlah Peserta yang hadir sebanyak 55 orang peserta terdiri dari 20 penguru masjid dibawah binaan IPIM Sumatera selatan serta 35 orang peserta secara daring berasal dari luar kota Palembang. Semua peserta dikumpulkan didalam satu ruangan bagi yang hadi secara luring dan sisanya 35 orang hadir secara daring melalui media zoom link dan siara langsung yout igm tv palembang.

\section{Evaluasi}

Tahap evaluasi merupakan penilaian setelah rangkaian kegiatan dilakukan oleh pelaksana sesuai dengan jadwal yang telah ditentukan. Evaluasi ini bisa berupa perbaikan atau saran untuk pelaksanaan kegiatan lebih baik lagi dan kelanjutan menjadi binaan kampus

\section{Simpulan}

Penyelenggaran kegiatan pengabdian kepada masyarakat ini menghasilkan peningkatan kemampuan peserta dalam pengelolaan dan pelaporan dana keuangan Masjid secara lebih baik, transparan, akuntabel, dengan melalui program aplikasi DKM yang menyajikan fitur-fitur pilihan terkait pengelolaan dan pelaporan dana masjid secara tersistematis dan informatif. Kegiatan ini juga memberikan kemampuan dasar peserta untuk setiap peserti memiliki email dan akses dasar pencarian di internet terkait aplikasi DKM yang digunakan dalam pengelolaan dan pertanggungjawaban keuangan masjid. 


\section{Daftar Pustaka}

“Sistem Informasi Masjid.” https://simas.kemenag.go.id/ (accessed Jun. 21, 2021)

Satu

Data

Sumatera

Selatan."

http://satudata.sumselprov.go.id/v3/data/index.php?q=Data-View\&s=90 (accessed Jun. 21, 2021).

"Direktori masjid dan platform manajemen masjid terlengkap di indonesia DKM.or.id." https://dkm.or.id/ (accessed Jun. 24, 2021). 